\title{
Threatened vertebrate species: associations between conservation actions, funding and population trends
}

\author{
David Luther ${ }^{1, *}$, Katherine Gentry ${ }^{2}$ \\ ${ }^{1}$ Biology Department and Smithsonian Mason School of Conservation, George Mason University, \\ 4400 University Dr. MS3E1 Fairfax, VA 22030, USA \\ ${ }^{2}$ Department of Biological Sciences, Purdue University, 915 West State Street, West Lafayette, IN 47907, USA
}

\begin{abstract}
There are more species threatened with extinction now that at any point in recent history. However, resources for species conservation can be limited, and awareness of gaps in knowledge and conservation action implementation is important when allocating funds and planning conservation efforts. Here, we explore the relationships between conservation action implementation, funding allocation, and population trends for all vertebrate species listed under the US Endangered Species Act. The same core suite of conservation actions (monitoring, habitat protection, and educational awareness) was implemented for most species. Our assessment of the effectiveness of funding and implemented conservation actions was impeded, however, because population trend information was lacking for many species. For instance, we found that marine species received 3 times more annual funding on average than continental species and 10 times more annual funding than species that live on islands, yet the population trends for the majority of marine species are decreasing or unknown. Furthermore, the number of marine species with increasing population trends is not significantly higher. Thus, we conclude more monitoring and reporting is needed to improve population trend information before the appropriateness of funding allocation and efficacy of conservation actions can be properly assessed.
\end{abstract}

KEY WORDS: Threatened species $\cdot$ Funding $\cdot$ Conservation actions

\section{INTRODUCTION}

We are currently in the midst of a global biological diversity crisis and the urgency to conserve species and prevent extinctions is now greater than ever (Baillie et al. 2008, Butchart et al. 2010, Barnosky et al. 2011, Pimm et al. 2014, Ceballos et al. 2015). Conservation actions, such as in situ and ex situ management practices and implementation of conservation policies, can help alleviate threats and reverse declining population trends of species threatened with extinction (Salafsky et al. 2008, Hoffmann et al. 2010, 2015, Luther et al. 2016a). However, conservation has often been criticized in regard to biases in conservation effort and resource allocation, with cer-

${ }^{*}$ Corresponding author: dluther@gmu.edu tain species or locations receiving a disproportionate amount of funding or attention (Wilcove et al. 1993, Leonard 2008, Gibbs \& Currie 2012, Gratwicke et al. 2012). Given the dire situation of many species, it is imperative that we maximize the implementation of effective conservation actions and understand biases in resource allocation.

Just as the proper assessment of threats is important for conservation planning, an awareness of gaps in conservation action implementation is important when allocating funds and planning conservation efforts (Evans et al. 2016, Gerber 2016). Some studies have also looked at the alignment between conservation actions recommended and those that are implemented (Luther et al. 2016b). While others have

(C) The authors 2019. Open Access under Creative Commons by Attribution Licence. Use, distribution and reproduction are unrestricted. Authors and original publication must be credited. 
assessed the implementation of conservation actions, the majority of studies only looked at one conservation action at a time rather than the suite of actions that are implemented together (but see Luther et al. 2016a). However, conservation actions are seldom implemented in isolation, and indeed, there are often several different actions needed to effectively conserve threatened species. It is therefore more insightful to study the efficacy of the overall conservation approach (i.e. the suite of conservation actions implemented).

In this study, we use conservation data to evaluate the conservation approach for vertebrate species listed under the US Endangered Species Act (ESA). In the USA, the ESA is the primary legislation to protect threatened species and the habitats on which they depend. The ESA requires the US Fish and Wildlife Service (USFWS) and the National Marine Fisheries Service (NMFS) to write a recovery plan and provide 5 year updates on the conservation progress of each listed species. Both agencies make conservation data publicly available in terms of implemented conservation efforts, funding, and population trends.

Our goal with this paper is to explore the relationships between conservation action implementation, funding, and population trends amongst taxa and between marine, island, and continental environments. An understanding of these relationships can help inform decisions and thus potentially improve the effectiveness of conservation action implementation in the future. Given the especially dire circumstances for endangered species on islands (Veitch et al. 2011), we predict greater implementation of conservation actions and funding for species on islands compared to marine and continental species. Given previous documentation of taxonomic biases, (Gratwicke et al. 2012) we predict that have fewer conservation actions will be implemented and less funding granted for amphibians than for other taxonomic groups investigated in the present study. Finally, we predict that regardless of taxonomic affiliation or location, species with more conservation actions implemented and greater funding are more likely to have positive conservation trends (Luther et al. 2016).

\section{METHODS}

\subsection{Data collection}

We collected data on conservation action implementation for all vertebrate species federally listed under the ESA. We did not include foreign species listed under the ESA (i.e. species not found in the USA). Species that have been delisted from the ESA were not included as their conservation actions are not in the USFWS database of conservation actions implemented (see below). When data were available for multiple populations of a listed species, the population information was summed so that the analysis would be at the level of the listing unit, not sub-populations within the listing unit. Sixty-seven species were excluded from the analysis, because they were listed as exempt from recovery, extinct, or did not have any conservation actions implemented according to the USFWS recovery online activity report (ROAR) databases (see Table S1 in Supplement 1 at www.intres.com/articles/suppl/n039p105_supp1.pdf for a list of all vertebrate species included, and those excluded from this study). All vertebrate species that had a recovery plan and conservation actions implemented as of January 2016 were included in the analysis.

Information on vertebrate species identity, 5 year reviews, and conservation expenditures were all found on publicly available USFWS websites. The ROAR database was accessed for birds, mammals, amphibians and reptiles between 15 September and 1 October 2015. Websites for fish were accessed in January 2016. The USFWS ROAR database (https://ecos.fws.gov/ ecp0/ore-input/ad-hoc-recovery-actions-public-reportinput) contained information on all implemented conservation actions at 5 year intervals from 1995 through 2014. The ROAR database categorizes conservation actions into the following categories: discontinued, complete, not started, obsolete, ongoing current, ongoing not current, partially complete, planned, and unknown. We only used conservation actions listed as complete; completed actions mean there has been time for actions to take effect and potentially influence the population trends. The ROAR database only identifies what conservation measures implemented in 5 year intervals. Although this means the data are analyzed at a coarse scale, it includes over 40 years to assess associations between what has been implemented and population trends of species. The data were used to identify which conservation actions have been implemented for each species and when they were implemented. The ROAR database lists descriptions of hundreds of different specific conservation actions that have been implemented. Each implemented conservation action was grouped into one of the following categories to reduce the variation into manageable units for analysis: enforce regulations, population monitoring, habitat restoration, habitat protection, invasive species control, ex situ, 
reintroduction, educational awareness, legislation, critical habitat designation, recovery plan (single- or multi-species) (after Salafsky et al. 2008, Luther et al. 2016b).

When available, population level information was collected from the USFWS 5 year review for each listed species, including the number of individuals and the number of populations, as well as the year. All data were conformed to the number of individuals for each species. For example, breeding pairs were multiplied by 2 for species reported in number of breeding pairs rather than number of individuals. Unfortunately, many species did not have population data available in 5 year reviews or any other source through USFWS. In such instances, the IUCN Red List of Threatened Species was consulted for population trend information to determine if a population was increasing, decreasing, stable, or unknown. Like the ROAR database, the population data are not available at a fine scale, but in up to 5 year increments; however, assessing hundreds of species over a 40 year timespan should allow us to detect relationships between these variables, even if they are at coarse scales.

Data on the amount of money spent on the conservation of each species in a given year were collected from the USFWS ESA library, www.fws.gov/endangered/esa-library/. Based on the available expenditure data from 1996 to 2014 we collected information on the total amount of money that the federal government spent for a species, the average amount of money spent in a year, and the number of years a species received funding.

Species were categorized as living on continents, islands, or in marine environments, because species in each respective environment often have different threats and require different conservation strategies. Freshwater species were grouped with continental or island species, depending on the environment in which they live. Some species inhabit 2 of these categories, such as sea turtles, salmon, and sea lions that are mostly marine but spend some time on land or in freshwater systems for reproduction. In such cases, species were categorized in accordance with the agency that manages their recovery, NMFS for marine species or USFWS for continental and island species, as they are ultimately responsible for conservation actions and management decisions involved with the recovery of the species. Island species included all ESA listed vertebrate species found on both oceanic islands, such as Puerto Rico, Guam, and Hawaii, and continental islands, such as the Channel Islands in California.

\subsection{Network analysis of conservation approach}

We use undirected network graphs to assess the connectedness of conservation action implementation for island, marine, and continental species. For each landmass, we created a biadjacency matrix consisting of conservation actions. The 'bipartite_projection' function of the igraph package in R (Csardi \& Nepusz 2006) created a bipartite projection of a 1-mode network of individual conservation actions by conservation actions shared among conservation plans. The resultant weighted adjacency matrix of the bipartite projection is the matrix product of the interaction matrix and its transpose. The igraph package 'plot' function, with the default Fruchterman-Reingold algorithm, depicted each network. The represented scale of node size and edge weight was adjusted to minimize node-node and node-edge overlap. Node size was set according to its degree of centrality, a nodescale measure of the number of conservation action plans that included a particular conservation action.

We also describe several network-scale measures, including the number of network components and network density. A network component is defined as a disconnected portion of the network, whereas network density is the number of realized ties between nodes out of the maximum number of ties possible. Finally, we use the modularity index, $Q$, to quantify the degree of community structure in each network (Girvan \& Newman 2002, Newman \& Girvan 2004, Newman 2006). Modularity is a measure of the proportion of ties that occur within communities, relative to the expected proportion if all ties were placed randomly. We used both agglomerative and divisive modularity optimization algorithms to detect network community partitions, or modules. Specifically, we ran the divisive edge.betweenness.community() algorithm (Newman \& Girvan 2004) and the hierarchical agglomerative fastgreedy.community() algorithm on each landmass network.

\subsection{Conservation action implementation, funding, and population trends}

To test for differences in implementation of conservation actions across taxa and landmass categories, we used a Fisher's exact test for count data using $R$ and the 'fifer' package to conduct a chi-square Bonferonni corrected post hoc test examining pairwise differences with the $\mathrm{p}$-value criteria for taxa changing from $<0.05$ to $<0.01$ and landmass from $<0.05$ to $<0.017$ (Fife 2017). 
One-way analysis of variance tests (ANOVAs) were used to test if the total amount of funding, the average annual funding, and the number of conservation actions implemented differed between taxa, or by landmass type. Data met assumptions of normality and homogeneity of variances based on results from a Levene's test. Tukey tests were used to distinguish significant differences between taxa and landmass categories. Similarly, we used oneway ANOVAs to test if the number of conservation actions implemented was associated with the total amount of funding or the average annual funding for a species. ANOVAs were also used to assess if funding was significantly associated with increasing or decreasing population trends, or species with single or multi species recovery plans.

We examined average annual funding and the implementation of each management action with binomial logistic regression models. Binomial logistic regression was also used to test for significant relationships between each action and increasing population trends. Population trend tests only included species with increasing population trends $(\mathrm{N}=51)$ and decreasing population trends $(\mathrm{N}=138)$, and did not include species with stable $(\mathrm{N}=41)$ or unknown population trends $(\mathrm{N}=79)$. The models were not tested using subsets of species per taxa or per landmass categories due to sample size limitations in terms of the number of species with population trend data. All statistical analyses were performed in $\mathrm{R}$ (version 3.2.3, R Development Core Team 2015).

\section{RESULTS}

\subsection{Network analysis of conservation approach}

There were 39, 18, and 130 unique combinations of conservation actions implemented per species on marine, continental, and island landmasses, respectively. All networks were fully connected, containing a single, non-modular component $(Q=0$, regardless of modularity optimization method). Network density was 0.97 for marine species and 1.0 for island and continental species.

A majority of species-specific conservation approaches in all 3 landmass categories included educational awareness (67-95\% of species), habitat protection (58-86\% of species), and monitoring (75-90\% of species) (Fig. 1). Each of the possible 2-way combinations of the 3 actions were co-specified in $54 \%$ of species on islands. Comparatively, $58 \%$ of continental species conservation actions included education

\section{a) Conservation approach for island species}

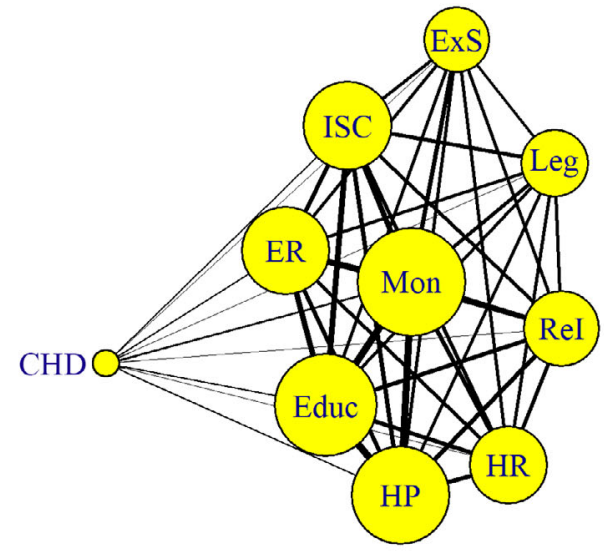

b) Conservation approach for marine species

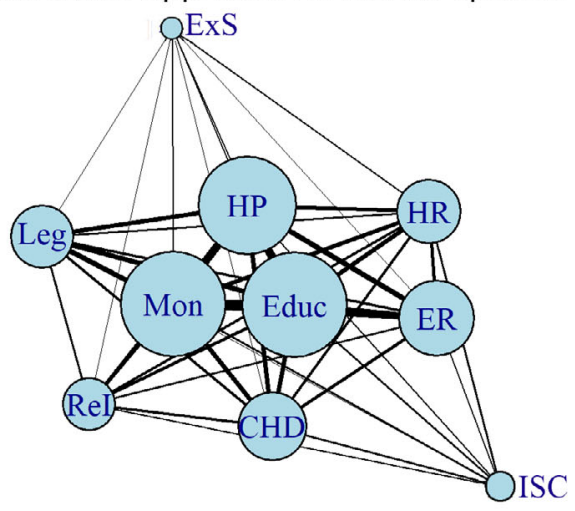

c) Conservation approach for continental species

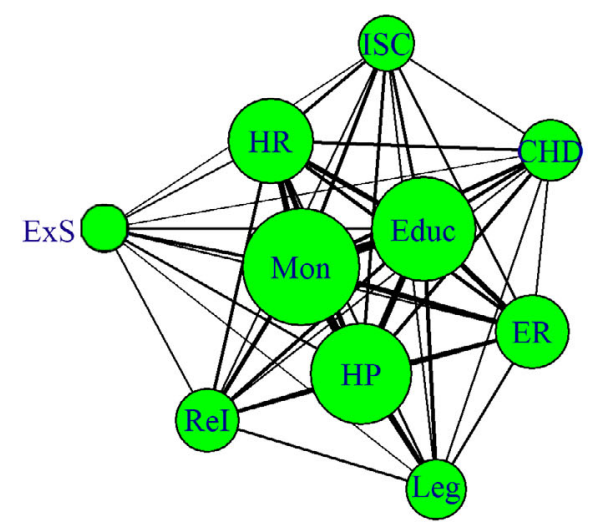

Fig. 1. Network graphs of conservation action implemented for (a) island, (b) marine, and (c) continental species. The nodes (circles) represent conservation actions, and weighted edges (lines) the number of conservation actions in which both nodes/conservation actions of a dyad are included. Leg: legislation; CHD: critical habitat designation; ISC: invasive species control; ExS: ex situ; ReI: reintroduction; HR: habitat restoration; HP: habitat protection; Mon: monitoring; Educ: education; ER: enforce regulations. Node size and edge is scaled at 10,25 , and $3 \%$ of original size for marine, island, and continental conservation actions networks, respectively 
and habitat protection; $71 \%$ included monitoring and habitat protection; and $69 \%$ included education and monitoring. In contrast, $81 \%$ of marine species had education and habitat protection, and habitat protection and monitoring implemented. However, dual implementation of education and monitoring was implemented for $91 \%$ of marine species.

\subsection{Conservation action implementation, funding, and population trends}

\subsubsection{Landmass categories}

There were notable differences in the implementation of specific conservation actions among landmass categories (Table 1). In particular, the conservation actions habitat restoration, critical habitat designation, and invasive species control were not implemented equally across landmass categories (Fisher's exact test, $\mathrm{p}=0.005 ; \mathrm{p}=0.003 ; \mathrm{p}=0.003$, respectively). Continental species had significantly more habitat restoration and critical habitat designation than species on islands (Bonferroni adjusted $\mathrm{p}$-values, $\mathrm{p}=0.0067$ and $\mathrm{p}=$ 0.0052, respectively). Species on islands had significantly more invasive species control implemented than continental species (Bonferroni adjusted p-value, $\mathrm{p}=0.0117$ ). In contrast, there were no significant differences in the implementation of regulation enforcement, ex situ, legislation, education, monitoring, or species reintroductions among landmass categories.

\subsubsection{Taxonomic groups}

Among taxonomic groups only the conservation actions educational awareness and legislation were implemented differently. Educational awareness was significant among the different taxa (Fisher's exact test, $\mathrm{p}=0.0002$ ), with significantly more educational awareness for mammal species than fish or bird species (Bonferroni adjusted $\mathrm{p}$-value, $\mathrm{p}=0.0005$ and $\mathrm{p}=$ 0.0021 , respectively). Legislation was not implemented equally across the taxa (Fisher's exact test, $\mathrm{p}<0.0001$ ), with fish having significantly more legislation implemented than amphibians or reptiles (Bonferroni adjusted $\mathrm{p}$-value, $\mathrm{p}=0.0003$ and $\mathrm{p}=$ 0.0026 , respectively) and mammals having significantly more legislation than amphibians (Bonferroni adjusted $p$-value, $p=0.0007$ ). There were no other significant differences in the implementation of the conservation actions between taxa (i.e. enforce regulations, ex situ, habitat protection, invasive species control, reintroduction, habitat restoration, monitoring, or critical habitat designation).

The total number of conservation actions implemented did not differ among taxa or landmass categories $\left(F_{304,4}=0.63, \mathrm{p}=0.64 ; F_{306,2}=1.52, \mathrm{p}=0.22\right.$, respectively). There was also no difference in the total number of actions implemented between types of recovery plans (single or multiple) $\left(F_{307,1}=0.40, \mathrm{p}=\right.$ 0.53), or between species with increasing and decreasing population trends $\left(F_{187,1}=0.01, \mathrm{p}=0.92\right)$.

\subsubsection{Population trends}

Overall, $17 \%$ of species had increasing population trends, $13 \%$ stable, $45 \%$ decreasing and $26 \%$ of species in this study had unknown population trends (Fig. 2). In general, species on islands were most likely to have declining population trends: 69\%, compared to $44 \%$ of marine and $37 \%$ of continental species. Population trends for amphibians were only

Table 1. Percentage of species with each class of conservation action and population trends by landmass and taxa categories

\begin{tabular}{|c|c|c|c|c|c|c|c|c|}
\hline \multirow{2}{*}{ Conservation action } & \multicolumn{3}{|c|}{ Environment } & \multirow[b]{2}{*}{ Amphibian } & \multirow[b]{2}{*}{ Bird } & - Taxa - & \multirow[b]{2}{*}{ Mammal } & \multirow[b]{2}{*}{ Reptile } \\
\hline & Continental & Island & Marine & & & Fish & & \\
\hline Education & 73.06 & 66.67 & 95.24 & 88.89 & 66.28 & 63.73 & 35.29 & 74.29 \\
\hline Enforce regulations & 47.95 & 49.28 & 57.14 & 55.56 & 51.16 & 44.12 & 44.12 & 62.86 \\
\hline Ex situ & 27.40 & 33.33 & 14.29 & 27.78 & 33.72 & 33.33 & 20.59 & 11.43 \\
\hline Habitat protection & 74.43 & 57.97 & 85.71 & 61.11 & 66.28 & 70.59 & 77.94 & 80.00 \\
\hline Habitat restoration & 57.99 & 36.23 & 42.86 & 50.00 & 48.84 & 64.71 & 42.65 & 42.86 \\
\hline Invasive species control & 31.05 & 50.72 & 19.05 & 33.33 & 45.35 & 29.41 & 29.41 & 34.29 \\
\hline Legislation & 36.53 & 30.43 & 52.38 & 0.00 & 27.91 & 50.00 & 47.06 & 14.29 \\
\hline Monitoring & 88.13 & 75.36 & 90.48 & 94.44 & 74.42 & 86.27 & 94.12 & 88.57 \\
\hline Reintroduction & 36.99 & 33.33 & 33.33 & 27.78 & 31.40 & 41.18 & 41.18 & 25.71 \\
\hline Critical habitat designated & 42.47 & 21.74 & 52.38 & 44.44 & 26.74 & 48.04 & 33.82 & 45.71 \\
\hline $\begin{array}{l}\text { No. of species with } \\
\text { conservation actions }\end{array}$ & 219 & 69 & 21 & 18 & 86 & 102 & 68 & 35 \\
\hline
\end{tabular}




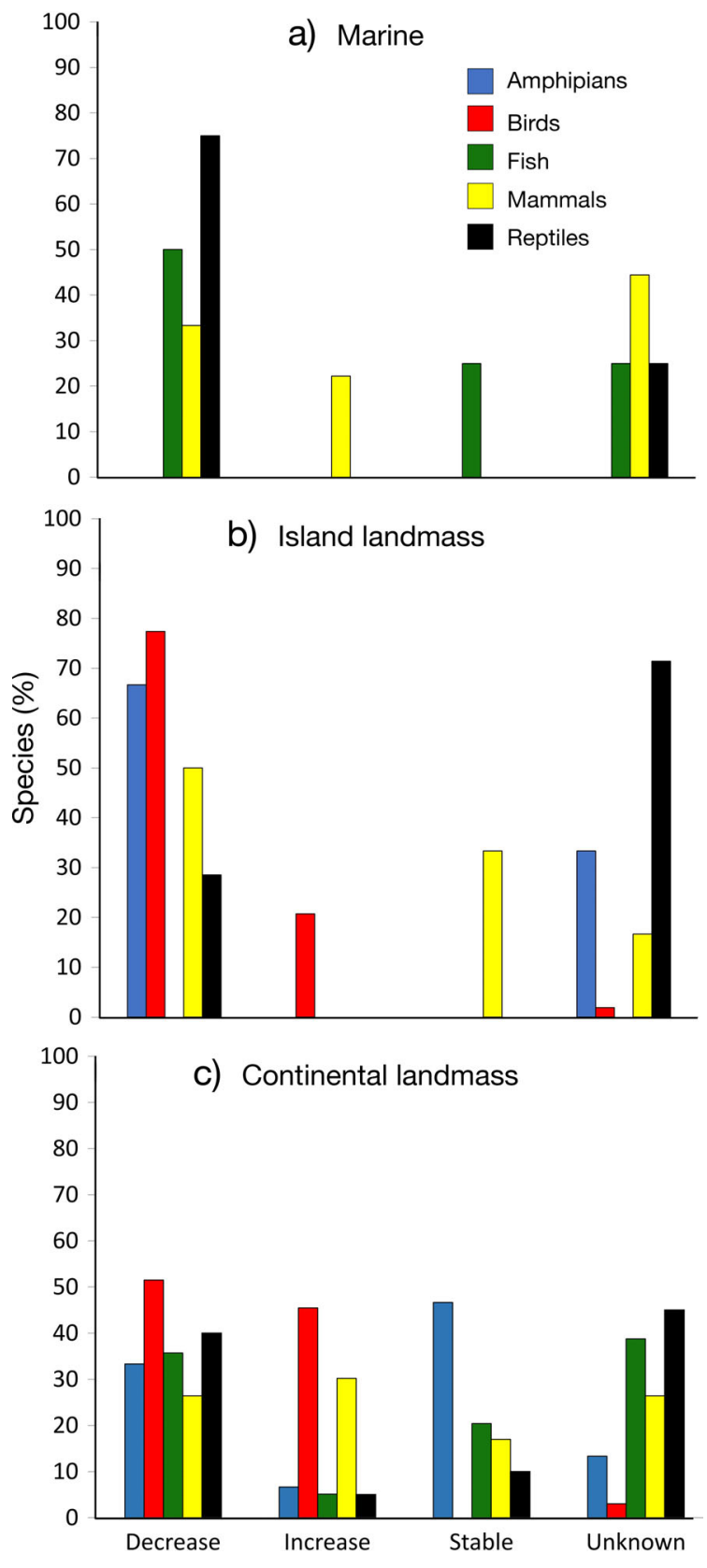

Fig. 2. Population trends of ESA-listed vertebrate species (a) in marine environments, (b) on islands, (c) in the continental US. Colored bars show population trends for amphibians, birds, fish, mammals, and reptiles. Across the board, the population trends for the majority of species are decreasing or unknown, especially for marine and island species

decreasing or unknown on islands, and the majority of island birds had decreasing population trends. For reptiles and mammals, population trends were decreasing or unknown on islands and in marine environments. Continental species had the most stable population trends, $18 \%$, compared to $4 \%$ of marine and $2 \%$ of island species. Twenty-two percent of marine species had increasing population trends while $16 \%$ of continental and island species had increasing population trends (Fig. 2).

Increasing population trends were positively associated with single species recovery plans $(\mathrm{N}=214)$ rather than multispecies recovery plans $(\mathrm{N}=95)$ $\left(\mathrm{Z}_{187}=2.70, \mathrm{p}=0.007\right)$. Binomial regression models revealed that none of the other implemented conservation actions were associated with increasing or decreasing population trends (see Table S2 in Supplement 1 for a full report of results).

\subsubsection{Funding}

There was no difference in the total amount of funding $\left(F_{304,4}=0.39, \mathrm{p}=0.8\right)$ or average annual funding between the different taxa $\left(F_{304,4}=0.44, \mathrm{p}=\right.$ 0.77 ) (Table 2). There were significant differences in the total amount of funding between the different landmass categories $\left(F_{306,2}=12.74, \mathrm{p}<0.001\right)$, with marine species receiving significantly more total funding than species on islands and on continents (Tukey's honestly significant difference [HSD], p < 0.001 , and $\mathrm{p}<0.001$, respectively). The average annual funding is also not equal across the different landmass categories $\left(F_{306,2}=14.09, \mathrm{p}<0.001\right)$, with marine species receiving significantly more funding on average than island and continental species (Tukey's HSD, $\mathrm{p}<0.001$ and $\mathrm{p}<0.001$, respectively).

The total amount of funding and the average annual funding was significantly higher for species with single species relative to multi species recovery plans $\left(F_{307,1}=10.1, \mathrm{p}=0.002 ; F_{307,1}=11.1, \mathrm{p}=0.001\right.$ ， respectively). There were no significant relationships between population trends and the total amount of funding or the average annual funding $(p=0.97$ and $\mathrm{p}=0.42$, respectively).

\section{DISCUSSION}

This study's investigation into the relationships between implemented conservation actions, funding, and population trends of threatened species revealed fewer than expected associations between these variables, but did indicate large funding discrepancies between threatened species in different landmass types. Specifically, we identified 3- and 10-fold differences in funding between species in marine compared to continental, and island locations, respectively. We also found a few differences in conservation action implementation based on landmass and 
Table 2. Number of years a species received funding, total funding, average annual funding for each species as allocated by the US government, and the average number of conservation actions per species by environment and taxa categories. Marine species received more total and annual average funding than continental or island species. There was no significant difference between the amount of funding and the average number of conservation actions among taxa. All values are mean $\pm \mathrm{SD}$

\begin{tabular}{|lcccc|}
\hline & $\begin{array}{c}\text { No. of years } \\
\text { a species } \\
\text { is funded }\end{array}$ & $\begin{array}{c}\text { Total funding } \\
\text { (US\$ million) } \\
\text { per species }\end{array}$ & $\begin{array}{c}\text { Average funding } \\
\text { (US million) } \mathrm{yr}^{-1} \\
\text { per species }\end{array}$ & $\begin{array}{c}\text { Actions } \\
\text { in place } \\
\text { per species }\end{array}$ \\
\hline $\begin{array}{l}\text { Environment } \\
\text { Continental }\end{array}$ & $14.74 \pm 4.34$ & $16.4 \pm 45.3$ & $1.1 \pm 3.1$ & $5.71 \pm 2.27$ \\
Island & $12.22 \pm 2.96$ & $3.2 \pm 5.10$ & $0.3 \pm 0.4$ & $5.19 \pm 3.24$ \\
Marine & $14.52 \pm 4.69$ & $57.2 \pm 75.6$ & $4.1 \pm 4.9$ & $6.10 \pm 2.39$ \\
& & & & \\
Taxa & & & & \\
Amphibian & $15.33 \pm 3.87$ & $4.6 \pm 9.7$ & $0.3 \pm 0.6$ & $5.83 \pm 2.20$ \\
Bird & $11.19 \pm 2.11$ & $15.8 \pm 33.6$ & $1.3 \pm 2.8$ & $5.27 \pm 3.23$ \\
Fish & $15.93 \pm 3.42$ & $18.2 \pm 56.7$ & $1.2 \pm 3.6$ & $5.69 \pm 2.27$ \\
Mammal & $13.78 \pm 5.90$ & $15.7 \pm 47.6$ & $1.1 \pm 3.1$ & $5.78 \pm 2.10$ \\
Reptile & $16.49 \pm 1.01$ & $19.1 \pm 31.5$ & $1.1 \pm 1.8$ & $5.89 \pm 2.23$ \\
\hline
\end{tabular}

taxonomic groups, though conservation plans for all species and locations tended to involve a combination of educational awareness, monitoring, and habitat protection. Unfortunately, the paucity of data on population trends for vertebrate species listed on the US ESA contributed to difficulties in analyzing and interpreting results related to population trends and the efficacy of implemented conservation actions.

\subsection{Implementation of conservation actions}

In general, we found greater parity than anticipated in terms of the conservation approach implemented in marine, island, and continental environments. Across environments, educational awareness, monitoring, and habitat protection were a core set of conservation actions implemented for the majority of listed species. There were large differences in the number of unique combinations of conservation actions implemented across the different environments, with islands having 130 unique combinations, while continental and marine species had 30 and 18 unique combinations, respectively. These discrepancies could be the result of different threats on different islands or could potentially result from less targeted species conservation approaches for marine and continental species. Either way, the relationships should be pursued in follow-up studies. Other actions, however, were implemented disproportionately among the different environment categories and taxonomic groups. For example, we observed that invasive species control was implemented more for species on islands compared to continental or marine species. This finding makes sense given that invasive species are one of the main threats to species on islands (Clavero \& García-Berthou 2005). Concentrated efforts to eradicate exotic invasive species on islands should thus have tangible benefits for threatened species on those islands (Veitch et al. 2011, Jones et al. 2016).

In comparison, the conservation approach for continental species more often involved habitat related conservation actions, such as habitat protection, critical habitat designation and habitat restoration (see Luther et al. 2016b). The reason behind this discrepancy is unclear but could be due to many contributing factors or differences in threats. For example, islands have less available habitat for protection or restoration, remaining habitat may already be preserved, or fewer expenditures for species on islands might prohibit these conservation actions from being implemented (Leonard 2008, Luther et al. 2016b), or the threats to habitat integrity are greater in continental systems. Nevertheless, habitat related conservation actions can have large benefits for species recovery (Wilcove \& Chen 1998, Taylor et al. 2005, Gibbs \& Currie 2012), especially on islands, where population trends are more likely to be in decline (Kier et al. 2009, Reed et al. 2012, Luther et al. 2016b).

Legislative actions and educational awareness efforts were not associated with specific environment categories but were greater for mammal and fish species than other taxonomic groups. In fact, marine mammals and game fish made up the majority of the species for which legislation and educational awareness actions were implemented. This bias could have arisen in an effort to overcome a long history of overharvesting in the United States (e.g. big game trophy hunting, fur trapping, systematic extermination, and unsustainable fishing practices; see Hutchings 2000, Leader-Williams \& Dublin 2000, Treves \& Karanth 2003, Hutchings \& Reynolds 2004). Legislation can be used to control the different types of overexploitation such as fishing or hunting, but legislation is also used, albeit controversially, to set maximal sustainable yields for commercial use and special-circumstance harvesting (Robinson \& Bennett 2004, Worm et al. 2009). While the present study did not find asso- 
ciations between educational awareness or legislation and population trend increases, Luther et al. (2016a) did find positive associations between both educational awareness and legislation and population trends for globally threatened bird species. Thus, in some contexts, these actions can have tangible results in terms of species recovery.

\subsection{Funding allocations}

Marine species received far more federal funding than continental or island species. The scale of the discrepancy between allocated funding for each environment was enormous, with marine species receiving 3 times more annual funding than continental species and 10 times more annual funding than species on islands. Previous research detected similar discrepancies between continental and island avian species but did not include all listed vertebrates or marine species (Leonard 2008, Luther et al. 2016b). The observed differences in funding allocations reflect either different levels of funding for agencies that oversee marine species (NMFS) and terrestrial species (USFWS) or fundamentally different cost needs for marine and terrestrial-based conservation actions. Alternatively, the discrepancy in funding could be that the marine species receive more funding per species because there are fewer of them, which allows for greater expenditures on each species. This situation could be further explained by the fact that marine species have single species recovery plans, whereas many terrestrial species are part of multi-species recovery plans, which have been shown to have greater funding allocation (Gibbs \& Currie 2012). There is strong evidence that recovery success tends to improve with increased expenditures (Miller et al. 2002, Scott et al. 2005, Ferraro et al. 2007, Gibbs \& Currie 2012, Luther et al. 2016b), yet the details of the relationship between funding and population recovery are still vague, and increased expenditures are not always equivalent with species recovery. For example, in our study the number of marine species with increasing population trends is only $5 \%$ higher than terrestrial species and not significantly different, despite a 10fold difference in funding. This finding warrants further exploration through the use of 'pressures-andconservation-impact' models or other evidence based models (see Possingham \& Gerber 2017, Waldron et al. 2017). For instance, Waldron et al. (2017) determined that conservation investment reduced biodiversity loss in over 100 countries using an evidencebased model that accounted for the effects of conservation investment and human development pressures. Thus, a similar analytical approach could be taken to understand how biodiversity loss changes with funding and conservation approach at a smaller scale, such as in marine versus terrestrial environments within the United States.

Species with single species recovery plans received more funding and were more likely to have positive population trends than species with multiple species recovery plans (see also Clark \& Harvey 2002, Gibbs \& Currie 2012). While designing multiple species recovery plans might be more practical for over-extended agencies (Clark \& Harvey 2002), it does not appear to facilitate species recovery. Species within multi-species plans are not all affected by the same threats, despite coexisting in the same region, and therefore do not necessarily benefit from conservation actions in the same way. While grouping species based on threat, in addition to taxonomy and environment type, will likely require more funding, it could improve the effectiveness of multispecies plans (Clark \& Harvey 2002).

While we used the best available funding data, there are several limitations to the funding data available from the USFWS regarding the annual expenditures on each ESA-listed species. The first of these limitations is that they only report state and federal expenditures and do not include expenditures from counties, cities, private sources, or non-profit groups, which can be substantial. Secondly, submission of state data to this database is voluntary, which could lead to biases in apparent funding for some species but not others. To avert this potential bias, we only included federal funding in the current study. We acknowledge that the funding data included in this paper are not the exact funding for each species, but it is the amount that the federal government has allocated for each species. By aggregating species by taxonomic order and environment categories we have attempted to look at broader trends in funding by these categories than for specific species, which should dilute any deficiencies in the data.

\subsection{Population trend data and knowledge gaps}

A relatively large portion of the vertebrate species had unknown or declining population trends. The paucity of species with increasing population trends partially explains the lack of association with funding or specific conservation actions. The fact that only $17 \%$ of 308 species in our study had positive population trends might explain why our results do not align 
with those of Taylor et al. (2005), who assessed all listed species, rather than just vertebrate species, and found that species with designated critical habitat were more likely to have increasing population trends.

Although other studies generally found a relationship between ESA tools, including listing, designation of critical habitat, development of recovery plans, and increasing population trends (Hoekstra et al. 2002, Scott et al. 2005, Langpap \& Kerkvliet 2010, Gibbs \& Currie 2012, Neel et al. 2012), differences between the current results and other studies could result from different sample sizes, methodologies, and taxa included in the studies. We used population trends reported in the USFWS status review, whereas earlier studies used the changes in population trend status from the USFWS biennial recovery reports to the US Congress (Taylor et al. 2005). The biennial reports do not provide as much detail as our method and potentially have a less broad view than the method that we used. In addition, the current study only looked at vertebrate species while others looked at all species listed under the ESA or only at specific taxa such as birds.

In a similar fashion as the present study, Taylor et al. (2005) focused on conservation actions for threatened species in Australia and found that threatened species had positive population trends when their range overlapped with protected areas, but they found no associations with other types of conservation actions. Potentially the efficacy of conservation actions other than habitat protection on population trends is too subtle for us to detect with current analyses or there are so many covariates that it is difficult to disentangle their effectiveness. Certainly, individual conservation actions are rarely implemented in isolation, and data collection at fine scales for such actions is not openly public, which makes tracking their effectiveness a difficult task.

Our analysis did not include ESA species that had been delisted during the period of analysis, as the conservation actions of these species were excluded from the ROAR USFWS dataset. Data on delisted species would have potentially provided valuable insight into the relationship between various conservation actions and changes in population trends. In addition, we did not include many species that were listed under the ESA but were either exempt from recovery or still did not have recovery plans. We recommend future efforts involve an investigation into which actions were instrumental in the recovery of these species to elucidate the most effective conservation strategies going forward.
One original intent of the present study was to assess the efficacy of conservation action implementation by assessing associations with population recovery. Upon inspection of the data, it became obvious there were not enough details for such an assessment. Moreover, the population trend data and the conservation action data were both too coarse for many species, with a minimum of reports at 5 year intervals for implementation of conservation actions as well as population data. In addition, the data were generally focused at the species level, but conservation actions often take place in specific populations, rather than for the whole species across its range. We encourage more detailed reporting of conservation data and population vital rates of threatened species so that conservation recovery can be properly and thoroughly assessed. This knowledge is crucial if we are to try and improve the standing of threatened species around the world.

Data archive. The dataset used in this study is available in Supplement 2 at www.int-res.com/articles/suppl/n039p105_ supp2.xlsx

Acknowledgements. The following undergraduate students at George Mason University helped collect the conservation action and funding data: Dianna Bellman, Andrea Broad, Christopher Fernandez, Emma Howes, and Shannon Pace. John Lamoreux provided insightful comments to earlier versions of the manuscript. The project was partially funded by the Virginia 4VA partnership and George Mason's URSP OSCAR program.

\section{LITERATURE CITED}

Baillie JEM, Collen B, Amin R, Resit Akcakaya H and others (2008) Toward monitoring global biodiversity. Conserv Lett 1:18-26

* Barnosky AD, Matzke N, Tomiya S, Wogan GOU and others (2011) Has the Earth's sixth mass extinction already arrived? Nature 471:51-57

* Butchart SHM, Walpole M, Collen B, van Strien A and others (2010) Global biodiversity: indicators of recent declines. Science 328:1164-1168

Ceballos G, Ehrlich PR, Barnosky AD, García A, Pringle RM, Palmer TM (2015) Accelerated modern human-induced species losses: entering the sixth mass extinction. Sci Adv 1:e1400253

Clark JA, Harvey E (2002) Assessing multi-species recovery plans under the Endangered Species Act. Ecol Appl 12: 655-662

Clavero M, García-Berthou E (2005) Invasive species are a leading cause of animal extinctions. Trends Ecol Evol 20: 110

Csardi G, Nepusz T (2006) The igraph software package for complex network research. InterJ Complex Syst 1695. https://igraph.org

Evans DM, Che-Castaldo JP, Crouse D, Davis FW and others (2016) Species recovery in the United States: in- 
creasing the effectiveness of the Endangered Species Act. Issues in Ecology, Vol 20. Ecological Society of America, Washington, DC

Ferraro PJ, McIntosh C, Ospina M (2007) The effectiveness of the US Endangered Species Act: an econometric analysis using matching methods. J Environ Econ Manage 54: 245-261

Fife D (2017) fifer: a biostatisticians toolbox for various activities, including plotting, data cleanup, and data analysis. R package version 1.1. https:/CRAN.Rproject.org/package $=$ fifer

Gerber LR (2016) Conservation triage or injurious neglect in endangered species recovery. Proc Natl Acad Sci USA 113:3563-3566

Gibbs KE, Currie DJ (2012) Protecting endangered species: Do the main legislative tools work? PLOS ONE 7:e35730

Gratwicke B, Lovejoy TE, Wildt DE (2012) Will amphibians croak under the Endangered Species Act? Bioscience 62: 197-202

Hoekstra JM, Clark JA, Fagan WF, Boersma PD (2002) A comprehensive review of Endangered Species Act recovery plans. Ecol Appl 12:630-640

*Hoffmann M, Hilton-Taylor C, Angulo A, Böhm M and others (2010) The impact and shortfall of conservation on the status of the world's vertebrates. Science 330:1503-1509

Hoffmann M, Duckworth JW, Holmes K, Mallon DP, Rodrigues ASL, Stuart SN (2015) The difference conservation makes to extinction risk of the world's ungulates. Conserv Biol 29:1303-1313

Hutchings JA (2000) Collapse and recovery of marine fishes. Nature 406:882-885

Hutchings JA, Reynolds JD (2004) Marine fish population collapses: consequences for recovery and extinction risk. Bioscience 54:297-309

Jones HP, Holmes ND, Butchart SHM, Tershy BR and others (2016) Invasive mammal eradication on islands results in substantial conservation gains. Proc Natl Acad Sci USA 113:4033-4038

Kier G, Kreft H, Lee TM, Jetz W and others (2009) A global assessment of endemism and species richness across island and mainland regions. Proc Natl Acad Sci USA 106:9322-9327

Langpap C, Kerkvliet J (2010) Allocating conservation resources under the Endangered Species Act. Am J Agric Econ 92:110-124

Leader-Williams N, Dublin HT (2000) Charismatic megafauna as 'flagship species'. In: Entwistle A, Dunstone N (eds) Priorities for the conservation of mammalian diversity: Has the panda had its day? Cambridge University Press, Cambridge, p 53-81

Luther DA, Brooks TM, Butchart SHM, Hayward MW, Kester ME, Lamoreux J, Upgren A (2016a) Determinants of bird conservation action implementation and associated population trends of threatened species. Conserv Biol 30:1338-1346

Luther D, Skelton J, Fernandez C, Walters J (2016b) Conser-

Editorial responsibility: Matt Hayward,

Bangor, UK vation action implementation, funding, and population trends of birds listed on the Endangered Species Act. Biol Conserv 197:229-234

Miller JK, Scott JM, Miller CR, Waits LP (2002) The Endangered Species Act: dollars and sense? Bioscience 52: 163-168

Neel MC, Leidner AK, Haines A, Goble DD, Scott JM (2012) By the numbers: How is recovery defined by the US Endangered Species Act? Bioscience 62:646-657

*Newman MEJ (2006) Modularity and community structure in networks. Proc Natl Acad Sci USA 103:8577-8582

Newman MEJ, Girvan M (2004) Finding and evaluating community structure in networks. Phys Rev E 69:026113

* Pimm SL, Jenkins CN, Abell R, Brooks TM and others (2014) The biodiversity of species and their rates of extinction, distribution, and protection. Science 344:1246752

* Possingham HP, Gerber LR (2017) Ecology: the effect of conservation spending. Nature 551:309

R Development Core Team (2015) R: a language and environment for statistical computing. R Foundation for Statistical Computing, Vienna

* Reed JM, DesRochers DW, VanderWerf EA, Scott JM (2012) Long-term persistence of Hawaii's endangered avifauna through conservation-reliant management. Bioscience 62:881-892

Robinson JG, Bennett EL (2004) Having your wildlife and eating it too: an analysis of hunting sustainability across tropical ecosystems. Anim Conserv 7:397-408

Salafsky N, Salzer D, Stattersfield AJ, Hilton-Taylor C and others (2008) A standard lexicon for biodiversity conservation: unified classifications of threats and actions. Conserv Biol 22:897-911

* Scott JM, Goble DD, Wiens JA, Wilcove DS, Bean M, Male T (2005) Recovery of imperiled species under the Endangered Species Act: the need for a new approach. Front Ecol Environ 3:383-389

Taylor MFJ, Suckling KF, Rachlinski JJ (2005) The effectiveness of the Endangered Species Act: a quantitative analysis. Bioscience 55:360-367

Treves A, Karanth KU (2003) Human-carnivore conflict and perspectives on carnivore management worldwide. Conserv Biol 17:1491-1499

Veitch CR, Clout MN, Towns DR (eds) (2011) Island invasives: eradication and management. Proc Int Conf Island Invasives. International Union for Conservation of Nature, Gland

W Waldron A, Miller DC, Redding D, Mooers A and others (2017) Reductions in global biodiversity loss predicted from conservation spending. Nature 551:364

*Wilcove DS, Chen LY (1998) Management costs for endangered species. Conserv Biol 12:1405-1407

Wilcove DS, McMillan M, Winston KC (1993) What exactly is an endangered species? An analysis of the US endangered species list: 1985-1991. Conserv Biol 7:87-93

* Worm B, Hilborn R, Baum JK, Branch TA and others (2009) Rebuilding global fisheries. Science 325:578-585

Submitted: August 2, 2018; Accepted: April 29, 2019

Proofs received from author(s): June 13, 2019 